\title{
Patient Use of Email, Facebook, and Physician Websites to Communicate with Physicians: A National Online Survey of Retail Pharmacy Users
}

\author{
Joy L. Lee, PhD, MS, MS ${ }^{1,2}$, Niteesh K. Choudhry, MD, PhD ${ }^{7}$, Albert W. Wu, MD, MPH', \\ Olga S. Matlin, $P h D^{3}$, Troyen A. Brennan, MD, JD ${ }^{3}$, and William H. Shrank, MD, MSHS ${ }^{1,3}$
}

\begin{abstract}
'Division of Pharmacoepidemiology and Pharmacoeconomics, Brigham and Women's Hospital and Harvard Medical School, Boston, MA, USA; ${ }^{2}$ Department of Health Policy \& Management, Johns Hopkins Bloomberg School of Public Health, Baltimore, MD, USA; ${ }^{3}$ CVS Health, Woonsocket, RI, USA.
\end{abstract}

BACKGROUND: Patient-physician communication often occurs outside the clinic setting; many institutions discourage electronic communication outside of established electronic health record systems. Little empirical data are available on patient interest in electronic communication and Web-based health tools that are technically feasible but not widely available.

RESEARCH OBJECTIVE: To explore patient behavior and interest in using the Internet to contact physicians. DESIGN: National cross-sectional online survey.

PARTICIPANTS: A sample of 4,510 CVS customers with at least one chronic condition in the household was used to target patients with chronic conditions and their caregivers. Subjects were identified from a national panel of over 100,000 retail pharmacy customers. Of those sampled, 2,252 responded (50.0\% response rate).

MAIN MEASURES: Survey measures included demographic and health information, patient use of email and Facebook to contact physicians, and patient interest in and use of Web-based tools for health.

KEY RESULTS: A total of $37 \%$ of patients reported contacting their physicians via email within the last six months, and $18 \%$ via Facebook. Older age was negatively associated with contacting physicians using email (OR 0.57 [95 \% CI 0.41-0.78]) or Facebook (OR 0.28 [0.17$0.45]$ ). Non-white race (OR 1.61 [1.18-2.18] and OR 1.82 [1.24-2.67]) and caregiver status (OR 1.58 [1.27-1.96] and OR 1.71 [1.31-2.23]) were positively associated with using email and Facebook, respectively. Patients were interested in using Web-based tools to fill prescriptions, track their own health, and access health information (37-57 \%), but few were currently doing so (4-8\%).

CONCLUSIONS: In this population of retail pharmacy users, there is strong interest among patients in the use of email and Facebook to communicate with their physicians. The findings highlight the gap between patient interest for online communication and what physicians may currently provide. Improving and accelerating the adoption of secure Web messaging systems is a possible solution that addresses both institutional concerns and patient demand.

Received June 5, 2014

Revised November 11, 2014

Accepted April 16, 2014

Published online June 24, 2015
KEY WORDS: communication; health information technology; patient preferences.

J Gen Intern Med 31(1):45-51

DOI: $10.1007 /$ s11606-015-3374-7

(C) Society of General Internal Medicine 2015

\section{BACKGROUND}

Patient-physician communication is a critical domain of the quality of care, ${ }^{1,2}$ and poor patient-physician communication is associated with poor patient health outcomes and low patient satisfaction. ${ }^{3,4}$ Technological advances over the past few decades have opened more avenues through which patients and physicians can communicate with one another; among them, email and social media are potential channels to enhance communication.

Yet the efficiency presented by email and social media sites like Facebook.com (hereafter referred to as Facebook) may not be enough to convince physicians to use them to communicate with patients. It is important, therefore, to understand patient interest in and expectations of the use of email and Facebook to communicate with their physicians, and how this may compare with policies guiding physician communication as well as what physicians themselves want and expect. Institutional policies generally restrict physician use of email and social media for patient communication in view of privacy and liability concerns. For example, the American College of Physicians (ACP) states that "e-communication between patients and physicians [...] requires discussion and previous agreement before electronic exchange is initiated." Although an estimated $20 \%$ of physicians communicate with their patients by email, anecdotal evidence suggests that many do not engage their patients in discussion about e-communication prior to its occurrence. ${ }^{6}$ Patients also appear more interested than their physicians in using online communication for clinical purposes, ${ }^{7-9}$ perhaps because they face fewer barriers to entry than physicians, who must juggle concerns of institutional guidelines, liability, and the intrusion on their time. ${ }^{7-9}$

According to the Pew Research Center, close to $90 \%$ of U.S. adults use the Internet, and among these, $72 \%$ visit social media websites like Facebook. ${ }^{10,11}$ Beyond socializing, users 
also turn to social media for health information; $12 \%$ of Internet users have reported accessing social media to research health issues. ${ }^{12}$ These surveys demonstrate the prevalence of Internet and social media use among American adults and the use of the Internet as a tool for health information. Several studies have examined the use of social media in different patient populations. For example, Greene et al. presented an early qualitative evaluation of diabetes groups on Facebook, ${ }^{13}$ and Baptist et al. examined the preferences of patients with asthma for managing their conditions with social media, text messaging, and email. ${ }^{14}$ Yet little is known about interest in online communication with physicians among patients with chronic conditions, especially with regard to the use of Facebook.

Accordingly, we examined patient interest and existing practices with regard to online communication with physicians, and characterized their interest in using email and physicians' websites for health purposes.

\section{METHODS}

We conducted a cross-sectional online survey of a nationwide sample of CVS customers living in households with at least one person with a chronic condition. The study was approved by the Brigham and Women's Hospital and Partners HealthCare Institutional Review Board.

\section{Sample Selection}

Survey respondents were customers of the CVS retail pharmacy, a large nationwide pharmacy chain, and were participants of the CVS e-Rewards consumer opinion panel ${ }^{15}$. CVS Health maintains a panel of 124,621 patients who have consented to participate in research and marketing activities. Similar panels have been used in research on medication adherence of caregivers ${ }^{15}$. The consumer panel was demographically balanced to reflect the U.S. population with regard to age, gender, annual household income, ethnicity, and geographic distribution. For their participation, respondents received small incentives, typically ranging from $\$ 2$ to $\$ 5$ in CVS ExtraBucks. A random sample of panelists who reported that they were over the age of 18 and lived in a household where either the respondent or another resident had a chronic condition (i.e. patients with chronic conditions and their caregivers) was targeted for the survey.

Survey results were collected during May and June 2013. Panelists were invited via email to participate in a survey on using the Internet to manage their health. The e-mail invited consumers to visit a website to participate in the survey, where they were further screened for eligibility.

Only complete responses were included in analyses; a $50 \%$ response rate was targeted, and enrollment was stopped once the target was achieved. The targeted response rate corresponded to a targeted sample size of at least 2,000 respondents. The calculation was made to guarantee precision in estimation as quantified by the confidence interval width. We aimed to provide adequate precision for subgroups as small as $15 \%$ of the sampled population with a confidence interval no wider than 0.1 (e.g., an estimate of $0.1[0.05,0.15]$ ).

\section{Survey Instrument}

The survey had 32 questions, including sections on respondent demographic and health information such as age, race, income, geographic region, health status, and the number and names of respondents' chronic conditions. The survey also asked respondents about their use of online and offline (i.e. in person or on the phone) health information sharing and their attitudes toward using the Internet for health-related purposes. This section included questions on the frequency with which respondents contacted their doctor or hospital within the last six months via a number of platforms; questions were assessed using five-point Likert-type scales that ranged from "Never" to "Once a week or more" for each activity and setting. Respondent attitudes about the quality and amount of health information online, whether and how such information should be trusted, and their interest in using Web-based tools for health purposes were also explored using five-point scales, with responses ranging from "Strongly disagree" to "Strongly agree" or "Not interested at all" to "Very interested," as appropriate.

The survey was constructed iteratively by the research team and piloted among public health professionals with expertise in social media in order to assess face validity.

\section{Analysis}

Descriptive statistics were calculated to characterize respondents and their responses. We used multivariate logistic regression models to assess the association between respondent characteristics and their use of email and Facebook to communicate with physicians. Regression analyses adjusted for demographic and other relevant covariates including age, sex, education, race, ethnicity, self-reported health status, caregiver status, having chronic conditions, and weekly Facebook use. Respondent use of email and Facebook were dichotomized as "never" or "any" use in the last six months. Analyses were conducted using Stata statistical software (Version 12; StataCorp LP, College Station, TX, USA).

\section{RESULTS}

\section{Patient Characteristics}

Overall, 4,510 advisory panelists were invited to participate in the survey. Of those, 2,252 respondents (50\%) were included in the analytic sample. A CONSORT (Consolidated Standards of Reporting Trials) diagram is used to describe the recruitment process (Fig. 1). The sample represented a broad range of age and income groups from across the United States (Table 1). 


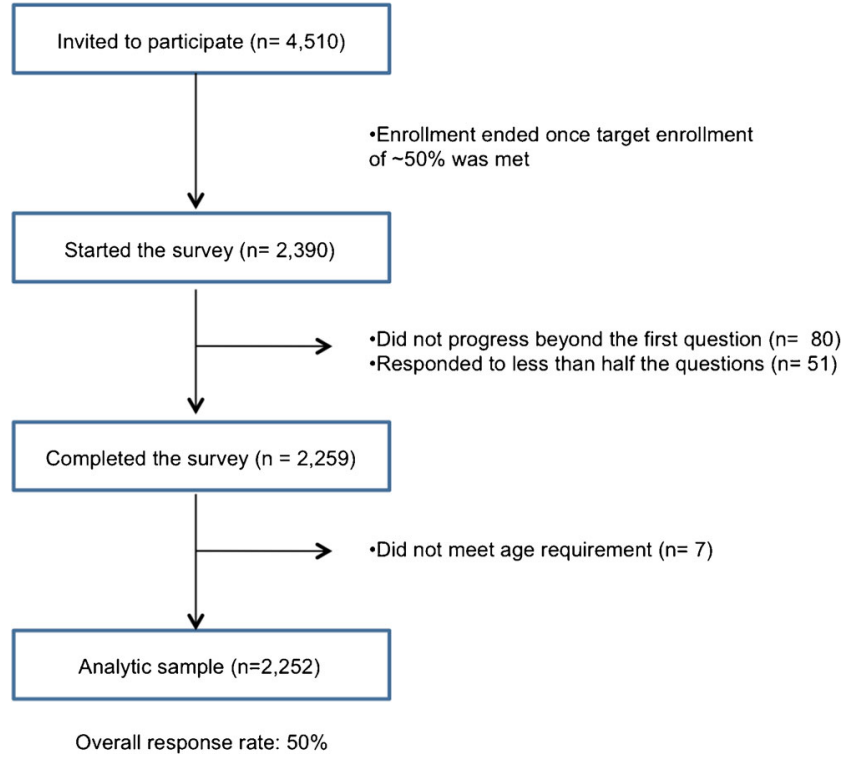

Figure 1 Enrollment of study patients.

Respondents tended to be well educated, in good health, and frequent users of Facebook. Compared to a national sample, this population was more female, less white, and had higher income.

\section{How Patients Communicate}

Respondents were asked how often they had "contacted [their] doctor or hospital" via email and how often via Facebook within the last six months. Thirty-seven percent of respondents reported that they had emailed their doctors or hospital; $18 \%$ reported contacting their doctors or hospital via Facebook. With the exception of the youngest respondent group (ages 18-24), which used email and Facebook less than respondents ages 25-44, use of both email and Facebook to contact physicians was inversely related to age group (Fig. 2); use of email was $49 \%$ among respondents $25-44$ years old, $34 \%$ for respondents 45-64 years old, and only $26 \%$ for respondents 65 years or older.

\section{Patient Communication Interest}

Respondents were asked about their level of interest in and use of methods for filling their prescriptions, tracking their health progress, and accessing their own health information via a number of Web-based tools, including email, their physician's website, mobile app, and Facebook. Table 2 displays the full results of patient interest and use. Forty-six percent reported being interested or very interested in filling their prescriptions via email while an additional $7 \%$ claimed that they already did so. Patients were also interested in using email to track health progress and access health information ( $46 \%$ and $46 \%$ ) while $4-5 \%$ of patients who already did so. Patient interest in using physicians' websites to contact access health information was highest among the four tools, at $57 \%$, with an additional $7 \%$ responding that they already do so.
Table 1 Characteristics of Respondents

\begin{tabular}{|c|c|c|c|}
\hline & $\begin{array}{l}\text { Number } \\
(n=2,252)\end{array}$ & Percentage & National data ${ }^{16-18}$ \\
\hline \multicolumn{4}{|l|}{ Age group (years) } \\
\hline $18-24$ & 396 & $18 \%$ & $13 \%$ \\
\hline $25-44$ & 721 & $32 \%$ & $34 \%$ \\
\hline $45-64$ & 676 & $30 \%$ & $35 \%$ \\
\hline $65+$ & 459 & $20 \%$ & $18 \%$ \\
\hline \multirow{2}{*}{\multicolumn{4}{|c|}{$\begin{array}{l}\text { Sex (male) } \\
\text { Education }\end{array}$}} \\
\hline & & & \\
\hline $\begin{array}{l}\text { High school } \\
\text { or less }\end{array}$ & 307 & $14 \%$ & $21 \%$ \\
\hline Some college & 617 & $28 \%$ & $37 \%$ \\
\hline College graduate & 705 & $32 \%$ & $27 \%$ \\
\hline Graduate school & 465 & $26 \%$ & $14 \%$ \\
\hline $\begin{array}{l}\text { Region } \\
\text { Northeast }\end{array}$ & 609 & $27 \%$ & $18 \%$ \\
\hline Midwest & 425 & $19 \%$ & $22 \%$ \\
\hline South & 845 & $38 \%$ & $37 \%$ \\
\hline West & 373 & $17 \%$ & $23 \%$ \\
\hline Hispanic & 289 & $13 \%$ & $16 \%$ \\
\hline \multicolumn{4}{|l|}{ Race } \\
\hline White & 1401 & $65 \%$ & $75 \%$ \\
\hline Black & 262 & $12 \%$ & $14 \%$ \\
\hline Asian & 325 & $15 \%$ & $6 \%$ \\
\hline Native American & 104 & $5 \%$ & $2 \%$ \\
\hline Other & 57 & $3 \%$ & $7 \%$ \\
\hline \multicolumn{4}{|c|}{ Total Household Income (\$) } \\
\hline$<20,000$ & 163 & $7 \%$ & $17 \%$ \\
\hline $20,000-39,000$ & 354 & $16 \%$ & $20 \%$ \\
\hline $40,000-59,000$ & 473 & $21 \%$ & $17 \%$ \\
\hline $60,000-79,000$ & 345 & $15 \%$ & $13 \%$ \\
\hline $80,000-99,000$ & 207 & $9 \%$ & $9 \%$ \\
\hline$>100,000$ & 351 & $16 \%$ & $23 \%$ \\
\hline $\begin{array}{l}\text { Prefer not to } \\
\text { specify }\end{array}$ & 359 & $16 \%$ & NA \\
\hline \multicolumn{4}{|l|}{ Self-described health } \\
\hline Excellent & 343 & $15 \%$ & $25 \%$ \\
\hline Very good & 1,418 & $63 \%$ & $33 \%$ \\
\hline Fair & 441 & $20 \%$ & $28 \%$ \\
\hline Poor & 50 & $2 \%$ & $3 \%$ \\
\hline \multicolumn{4}{|c|}{ Doctor's visits in the last 6 months } \\
\hline 0 visits & 212 & $9 \%$ & $27 \%$ \\
\hline 1 visit & 525 & $23 \%$ & $26 \%$ \\
\hline 2 visit3 & 590 & $26 \%$ & $13 \%$ \\
\hline 3 visits & 362 & $16 \%$ & $9 \%$ \\
\hline 4 visits & 181 & $8 \%$ & $6 \%$ \\
\hline$>4$ visits & 382 & $17 \%$ & $20 \%$ \\
\hline \multicolumn{4}{|l|}{ Chronic conditions } \\
\hline Allergies & 682 & $30 \%$ & NA \\
\hline Hypertension & 653 & $29 \%$ & $33 \%$ \\
\hline High cholesterol & 538 & $24 \%$ & $32 \%$ \\
\hline Depression & 262 & $12 \%$ & $16 \%$ \\
\hline Diabetes & 281 & 13 & 10 \\
\hline Heart disease & 135 & 6 & 21 \\
\hline Caregiver & 734 & 33 & 29 \\
\hline Married & 1,275 & 57 & 52 \\
\hline Children in household & 940 & 42 & 41 \\
\hline
\end{tabular}

\section{Correlates of Use}

Patient use of email and Facebook to communicate with their doctors was associated with a number of demographic factors (Table 3). Older patients were significantly less likely to use either email or Facebook to contact their doctors (odds ratio [OR] 0.57 and $0.28,95 \%$ confidence interval [CI] 0.41-0.78 and $0.17-0.45$, respectively). Non-white respondents were significantly more likely than white respondents to use email or Facebook to contact their physicians. Lower education attainment appeared to be negatively associated with emailing physicians, though the relationship was not consistent for 


\section{Communication with Providers}

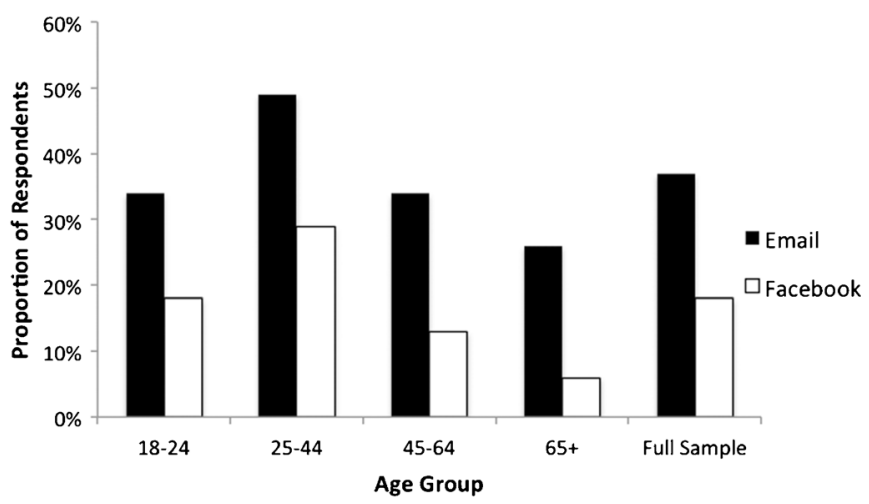

Figure 2 Communication with physicians within the last six months, by mode.

using Facebook. Instead, compared to college graduates, both respondents with lower and higher education attainment — some college and graduate degrees — were significantly less likely to have used Facebook to contact their doctors. Similarly mixed results were observed with income. Respondents in the lowest income quintile used email and Facebook to contact their physicians significantly less than respondents with higher incomes (OR 0.60 and $0.48,95 \% \mathrm{CI}$ $0.39-0.92$ and $0.28-0.83$, respectively). Caregivers and those with chronic conditions also had significantly higher odds of contacting doctors via email and Facebook; patients in fair health (but not poor health) had significantly higher odds of contacting their doctors compared to those in good health.

\section{DISCUSSION}

This study revealed strong patient interest and surprisingly high use of email and Facebook for communicating with their physicians. The results also highlight generational differences in how patients use Web technology to communicate with physicians: patients younger than 45 use the Web to contact their physicians at significantly higher rates than older patients. In contrast, previous studies have demonstrated physician resistance to adopting email and social media for clinical

Table 2 Interest and Use in Interacting with Physicians Online, by Mode

\begin{tabular}{|c|c|c|c|c|c|}
\hline & Purpose & Email & Website & $\begin{array}{l}\text { Mobile } \\
\text { App }\end{array}$ & Facebook \\
\hline \multirow[t]{3}{*}{$\begin{array}{l}\text { Use } \\
(\%)\end{array}$} & $\begin{array}{l}\text { Fill } \\
\text { prescription }\end{array}$ & 7 & 7 & 7 & 3 \\
\hline & $\begin{array}{l}\text { Track health } \\
\text { progress }\end{array}$ & 4 & 4 & 6 & 3 \\
\hline & $\begin{array}{l}\text { Access health } \\
\text { information }\end{array}$ & 5 & 7 & 3 & 3 \\
\hline \multirow[t]{3}{*}{$\begin{array}{l}\text { Interest } \\
(\%)\end{array}$} & $\begin{array}{l}\text { Fill } \\
\text { prescription }\end{array}$ & 46 & 51 & 41 & 16 \\
\hline & $\begin{array}{l}\text { Track health } \\
\text { progress }\end{array}$ & 37 & 44 & 40 & 18 \\
\hline & $\begin{array}{l}\text { Access health } \\
\text { information }\end{array}$ & 46 & 57 & 41 & 15 \\
\hline
\end{tabular}

communications - suggesting a discrepancy between patient expectations and physician practice..$^{7-9,19}$

In line with data from the Pew Research Center's Internet \& American Life Project, which found that $85 \%$ of U.S. adults used the Internet and that $61 \%$ looked for health information online, our study results indicate substantial patient interest in using online tools to manage their health and communicate with physicians. ${ }^{12,20}$ Yet despite their expressed interest for these opportunities, many of which are possible through electronic health records (EHR) systems developed and used by many major hospitals, few patients are doing so. While $57 \%$ of patients reported an interest in electronic access, only $7 \%$ reported accessing their own health information online. These results highlight the disconnect between patient interest and use, and suggest that patients are perhaps not aware of existing services.

The fact that $18 \%$ of respondents reported contacting physicians using Facebook is notable, given that most institutions actively discourage social media contact with individual patients. $^{5}$ Even the $7 \%$ rate of use among patients over 65 is impressive, since the percentage might grow as the average age of Facebook users rises and familiarity with Facebook increases. This finding is limited by the fact that we do not know how physicians reacted to being contacted or the nature of any communication. The survey was restricted to patient behavior, so we cannot make claims about physician use of email and Facebook. However, these findings do suggest a potential discrepancy between patient interest in communicating with physicians and institutional policies on social media.

Although the percentage of patients contacting their physicians via Facebook was unexpectedly high, the fact that patients are attempting to do so was not surprising, given that $72 \%$ of online adults use Facebook. ${ }^{10}$ It is important to note that this figure should not be interpreted as an estimate of interest among the general U.S. population, but as a signal of the interest in contacting physicians via Facebook by Internetsavvy patients. Though data on contact between physicians and patients on Facebook are scarce, patient interest in using Facebook to communicate with physicians has been 
Table 3 Results of Logistic Regression Assessing the Relationship Between Patient Characteristics and Odds of Ever Contacting Physicians Via Email and Facebook in the Previous 6 Months (Bold Indicates Statistical Significance at $\mathbf{p}<0.05$ Level)

\begin{tabular}{|c|c|c|c|c|}
\hline & \multicolumn{2}{|c|}{ Contact physicians via email $(n=1,829)$} & \multicolumn{2}{|c|}{$\begin{array}{l}\text { Contact physicians via Facebook } \\
(\mathrm{n}=1,829)\end{array}$} \\
\hline & Odds ratio & $95 \%$ CI & Odds ratio & $95 \%$ CI \\
\hline \multicolumn{5}{|l|}{ Age (years) } \\
\hline $18-24$ & 0.96 & $0.70-1.32$ & 0.91 & $0.63-1.33$ \\
\hline $25-44$ & Reference & & Reference & \\
\hline $45-64$ & 0.67 & $0.52-0.87$ & 0.40 & $0.29-0.56$ \\
\hline 65 and above & 0.57 & $0.41-0.78$ & 0.28 & $0.17-0.45$ \\
\hline Male & 1.08 & $0.87-1.35$ & 1.26 & $0.96-1.67$ \\
\hline \multicolumn{5}{|l|}{ Education } \\
\hline High school or less & 0.61 & $0.43-0.87$ & 1.02 & $0.67-1.56$ \\
\hline Some college & 0.62 & $0.48-0.81$ & 0.66 & $0.47-0.91$ \\
\hline College & Reference & & Reference & \\
\hline Graduate school & 0.90 & $0.68-1.17$ & 0.54 & $0.38-0.77$ \\
\hline \multicolumn{5}{|l|}{ Race } \\
\hline White & Reference & & Reference & \\
\hline Black & 1.61 & $1.18-2.18$ & 1.82 & $1.24-2.67$ \\
\hline Asian & 2.87 & $2.14-3.83$ & 3.31 & $2.38-4.59$ \\
\hline American Indian & 1.84 & $1.18-2.88$ & 3.31 & $2.01-5.43$ \\
\hline Other & 0.62 & $0.30-1.31$ & 0.91 & $0.35-2.36$ \\
\hline Hispanic & 1.10 & $0.78-1.55$ & 0.81 & $0.52-1.28$ \\
\hline \multicolumn{5}{|l|}{ Household income (\$) } \\
\hline$<20,000$ & 0.60 & $0.39-0.92$ & 0.48 & $0.28-0.83$ \\
\hline $20,000-39,999$ & 0.58 & $0.42-0.80$ & 0.50 & $0.33-0.75$ \\
\hline $40,000-59,999$ & Reference & & Reference & \\
\hline $60,000-79,999$ & 0.93 & $0.68-1.26$ & 0.93 & $0.65-1.33$ \\
\hline $80,000-99,999$ & 1.09 & $0.77-1.58$ & 1.00 & $0.65-1.53$ \\
\hline$>100,000$ & 0.84 & $0.61-1.17$ & 0.37 & $0.23-0.60$ \\
\hline \multicolumn{5}{|l|}{ Self-described health } \\
\hline Excellent & 0.92 & $0.67-1.25$ & 0.70 & \\
\hline Good & Reference & & Reference & \\
\hline Fair & 1.45 & $1.12-1.88$ & 1.44 & $1.06-1.95$ \\
\hline Poor & 1.09 & $0.55-2.17$ & 0.48 & $0.16-1.45$ \\
\hline Caregiver & 1.58 & $1.27-1.96$ & 1.71 & $1.31-2.23$ \\
\hline Weekly Facebook use & 1.50 & $1.14-1.97$ & 1.36 & $0.94-1.96$ \\
\hline Chronic condition & 2.04 & $1.48-2.81$ & 1.77 & $1.16-2.71$ \\
\hline
\end{tabular}

documented. A 2011 survey on young asthma patients by Baptist and colleagues found that $59 \%$ of patients were interested in receiving information from their doctors via email, and $23 \%$ were interested in doing so via Facebook. ${ }^{14}$ In a 2012 letter, Pereyra-Elias et al. described a survey of Peruvian physicians in which they found that among the 121 respondents, $14 \%$ of Facebook users were 'Facebook friends' with their patients. ${ }^{21}$ Lastly, a 2009 survey by Moubarak et al. revealed that $15 \%$ of medical residents in their survey would not automatically decline a Facebook friend request from a patient, acknowledging not only that patients may contact their physicians via Facebook, but that some physicians may consider reciprocating. ${ }^{9}$

Secure messaging is now provided in many EHR systems. ${ }^{22}$ This technology allows patients and physicians to email each other in a data-secure environment, and its availability is likely to increase in the coming years. The Medicare and Medicaid EHR Incentive Programs, which provide financial incentives for meaningful adoptions of EHR technology, specifies patient use of secure messaging portals as a criteria for Stage 2 meaningful use. ${ }^{23}$ However, despite the increasing availability of secure portals, many patients will likely continue to prefer the convenience of personal email and Facebook to the use of portals. The very features of secure messaging portals that make them secure, such as restrictive passwords and the requirement of additional logins, can be deterrents to use for patients who prefer the convenience of personal email and social networking accounts. ${ }^{24}$ For example, a 2014 Institute of Medicine report on patient use of sites like Facebook found that while $76 \%$ of American social media users worried that the health information they shared could be used against them, their interest in sharing this information online in order to improve their healthcare and the care of others far outweighed their concerns about data security. ${ }^{25}$ These data reinforce our findings of strong patient interest in electronic communications with their physicians and the need for secure yet easy-to-use communication technologies.

The generalizability of the survey sample in our study is both a strength and a limitation. Since our sample was selected from retail chain pharmacy users, Americans who do not use retail chain pharmacies are underrepresented. Previous studies have shown that chains are less prevalent in the lowest-income regions. ${ }^{26}$ Our use of a Web-based survey may have also introduced bias. Although Internet use is prevalent among U.S. adults, those who respond to Internet surveys may differ from other patients - in particular, they may be more technologically savvy than the general population. This may have led us to overestimate 
the frequency of email and Facebook use and the level of patient interest in using those means to communicate with physicians. Thus, we would not generalize these findings to all Americans. Rather, we would expect them to be more representative of a population of Internet-facile consumers. Our respondents were also more likely to be female, Asian, and have higher income as compared to nationally representative data available from the national census and 2012 Medical Expenditure Panel Survey (MEPS). Despite these differences, however, these respondents matched closely with national data in terms of age, geographic distribution, ethnicity, doctor visits, and the presence of chronic diseases such as hypertension and diabetes. While we must exercise caution in generalizing to the entire U.S. population, we can nevertheless draw useful conclusions from a national sample of online-savvy retail pharmacy consumers.

As with any cross-sectional study, this survey does not allow us to make any statements on the causality of online social media use for health purposes. However, it does provide a more detailed description than previously reported of the ways in which consumers are using online social media with respect to their health. Our survey is also limited by its narrow focus on patient interest in communicating with their doctors rather than with other non-physician primary care providers. In negotiating between brevity and depth, we chose the term 'doctor' because it was easiest for respondents to conceptualize without additional explanations. As previously stated, this study focused on patient behaviors in communicating with their physicians. Therefore, we cannot comment on how physicians are using social media to communicate with their patients and whether physicians are reciprocating patient communications via Facebook. These questions require further examination.

This paper highlights the considerable interest patients have in using Internet tools to communicate with their physicians. Given the importance that patients place on having access to their physicians, physicians and their institutions should consider how best to permit and reinforce the use of these channels. This interest in the use of email and Facebook to manage health and to communicate with physicians also illustrates the need for physicians to adopt widely used technologies for clinical communication while ensuring data security. Adoption would also allow physicians to take advantage of situations where patients are engaged in communicating with physicians. Patient interest suggests that, rather than prohibiting the use of social media between physicians and patients, physicians and patients alike should be educated on the proper use of social media and how this tool may be harnessed for clinical communication. Improvements can be made in raising patient awareness of services that may already be available online, such as refilling prescriptions or accessing health information. Moreover, this study raises questions as to how physicians should best address patient interest in using email and Facebook to communicate with one another, and the proper steps to undertake in drawing communication expectations and boundaries within the context of new technologies. Future research could assess physician responses to patient requests over social media platforms like Facebook.

ACKNOWLEDGMENTS: This study was supported by an unrestricted research grant from CVS Health to Brigham and Women's Hospital.

Conflict of Interest: Drs. Olga Matlin, Troyen Brennan, and William Shrank are employees of CVS Health. Dr. Choudhry is a consultant to Mercer Health and Benefits, Inc. The authors have no additional conflicts of interest.

Corresponding Author: Joy L. Lee, PhD, MS, MS; Department of Health Policy ManagementJohns Hopkins Bloomberg School of Public Health, 624 North Broadway, Baltimore, MD 21295, USA (e-mail: jllee@jhsph.edu).

\section{REFERENCES}

1. Boland BJ, Scheitel SM, Wollan PC, Silverstein MD. Patientphysician agreement on reasons for ambulatory general medical examinations. Mayo Clin Proc. 1998;73(2):109-117. doi:10.1016/S0025-6196(11) 63641-0.

2. Greer RC, Cooper LA, Crews DC, Powe NR, Boulware LE. Quality of patient-physician discussions about CKD in primary care: a crosssectional study. Am J Kidney Dis. 2011;57(4):583-591. doi:10.1053/j. ajkd.2010.08.027.

3. Bartlett EE, Grayson M, Barker R, Levine DM, Golden A, Libber S. The effects of physician communications skills on patient satisfaction; recall, and adherence. J Chronic Dis. 1984;37(9-10):755-764.

4. Wanzer MB, Booth-Butterfield M, Gruber K. Perceptions of health care providers' communication: relationships between patient-centered communication and satisfaction. Health Commun. 2004;16(3):363-383. doi:10.1207/S15327027HC1603_6.

5. Farnan JM, Sulmasy LS, Worster BK, et al. Online medical professionalism: patient and public relationships: policy statement from the American College of Physicians and the Federation of State Medical Boards. Ann Intern Med. 2013;158(8):620-627.

6. Menachemi N, Prickett CT, Brooks RG. The use of physician-patient email: a follow-up examination of adoption and best-practice adherence 2005-2008. J Med Internet Res. 2011;13(1), e23. doi:10.2196/jmir. 1578.

7. Virji A, Yarnall KSH, Krause KM, et al. Use of email in a family practice setting: opportunities and challenges in patient- and physician-initiated communication. BMC Med. 2006;4(1):18. doi:10.1186/1741-7015-4-18.

8. Singh H, Fox SA, Petersen NJ, Shethia A, Street RL. Older patients' enthusiasm to use electronic mail to communicate with their physicians: cross-sectional survey. J Med Internet Res. 2009;11(2), e18. doi:10.2196/ jmir. 1143.

9. Moubarak G, Guiot A, Benhamou Y, Benhamou A, Hariri S. Facebook activity of residents and fellows and its impact on the doctor-patient relationship. J Med Ethics. 2011;37(2):101-104. doi:10.1136/jme.2010. 036293.

10. Pew Research Center. Internet User Demographics. 2013. Available at: http://www.pewinternet.org/data-trend/internet-use/latest-stats /. Accessed 2 Apr 2015

11. Brenner J, Smith A. $72 \%$ of Online Adults Are Social Networking Site Users. 2014. Available at: http://www.pewinternet.org/2013/08/05/72of-online-adults-are-social-networking-site-users/. Accessed 2 Apr 2015

12. Fox S, Jones S. The social life of health information. 2009 Available at: http://www.pewinternet.org/ /media//Files/Reports/2009/PIP_Health_ 2009.pdf. Accessed 2 Apr 2015

13. Greene JA, Choudhry NK, Kilabuk E, Shrank WH. Online social networking by patients with diabetes: a qualitative evaluation of communication with facebook. J Gen Intern Med. 2011;26(3):287-292. doi:10. 1007/s11606-010-1526-3.

14. Baptist AP, Thompson M, Grossman KS, Mohammed L, Sy A, Sanders GM. Social media, text messaging, and email-preferences of asthma patients between 12 and 40 years old. J Asthma. 2011;48(8):824-830. doi:10.3109/02770903.2011.608460. 
15. Shrank WH, Liberman JN, Fischer MA, et al. Are caregivers adherent to their own medications? J Am Pharm Assoc (2003). 2011;51(4):492-498. doi:10.1331/JAPhA.2011.10006.

16. Yamin CK, Emani S, Williams DH, et al. The digital divide in adoption and use of a personal health record. Arch Intern Med. 2011;171(6):568 574. doi:10.1001/archinternmed.2011.34.

17. National Alliance for Caregiving. Caregiving in the US. Available at: http:// www.caregiving.org/data/CaregivingUSAllAgesExecSum.pdf. Accessed 2 Apr 2015

18. Yamin CK, Emani S, Williams DH, et al. The digital divide in adoption and use of a personal health Record adoption and use of a personal health record. Arch Intern Med. 2011;171(6):568-574. doi:10.1001/ archinternmed.2011.34.

19. Weitzman ER, Cole E, Kaci L, Mandl KD. Social but safe? Quality and safety of diabetes-related online social networks. J Am Med Inform Assoc. 2011;18(3):292-297. doi:10.1136/jamia.2010.009712.

20. Fox S, Duggan M. Mobile Health 2012. 2012. Available at: http://www pewinternet.org/ /media//Files/Reports/2012/PIP_MobileHealth2012_ FINAL.pdf
21. Pereyra-Elias R, Nizama-Via A, Mayta-Tristán P. Facebook use by Peruvian physicians: exposing private life to patients. Med Princ Pract. 2012;21(2):193-193. doi:10.1159/000332571.

22. Meaningful use and the patient portal: patient enrollment, use, and satisfaction with patient portals at a later-adopting center. Am J Med Qual. 2014. doi:10.1177/1062860614523488.

23. Centers for Medicare Medicaid Services. Stage 1 vs. Stage 2 Comparison Table for Eligible Professionals. CMS. 2012. Available at: http://www.cms. gov/Regulations-and-Guidance/Legislation/EHRIncentivePrograms / Stage_2.html. Accessed 2 Apr 2015

24. Hsiao AL, Bazzy-Asaad A, Tolomeo C, Edmonds D, Belton B, Benin AL. Secure web messaging in a pediatric chronic care clinic: a slow takeoff of "kids' airmail". Pediatrics. 2011;127(2):e406-13. doi:10.1542/peds.20101086

25. Grajales F, Clifford D, Loupos P, Okun S, Quattrone S. Social networking sites and the continuously learning health system: a survey. 2014.

26. Gellad WF, Choudhry NK, Friedberg MW, Brookhart MA, Haas JS, Shrank WH. Variation in drug prices at pharmacies. Health Serv Res. 2009;44(2p1):606-617. doi:10.1111/j.1475-6773.2008.00917.x. 